\title{
GC/MS Analysis of Some Bioactive Constituents from Carthamus lanatus $\mathbf{L}$.
}

Maya Mitova ${ }^{\mathrm{a}}$, Rilka Taskova ${ }^{\mathrm{b}}$, Simeon Popova ${ }^{\mathrm{a}}$, Ralf Günter Berger ${ }^{\mathrm{c}}$,

Ulrich Krings ${ }^{\mathrm{c}}$, and Nedjalka Handjieva ${ }^{\mathrm{a}^{*}}$

a Institute of Organic Chemistry with Centre of Phytochemistry, Bulgarian Academy of

Sciences, 1113 Sofia, Bulgaria. Fax: ++3592-8700225. E-mail: nechy@orgchm.bas.bg

b Institute of Botany, Bulgarian Academy of Sciences, 1113 Sofia, Bulgaria

c Institut für Lebensmittelchemie, Universität Hannover, 30453 Hannover, Germany

* Author for correspondence and reprint requests

Z. Naturforsch. 58c, 697-703 (2003); received January 22/March 7, 2003

Sterols, triterpenes, volatiles, polar and other constituents in aerial parts of Carthamus lanatus were analyzed by gas chromatography-mass spectrometry. Over 90 compounds were identified most of them new for the species. Sitosterol and stigmasterol were the most abundant of 10 sterols identified in the sterol fraction. Taraxasterol, $\alpha$ - and $\beta$-amyrine prevailed in the triterpene fraction. Volatiles, sterols and a fraction of the dichloromethane extract showed strong cytotoxicity (Artemia salina assay).

Key words: Carthamus lanatus, GC/MS Analysis, Cytotoxic Activity

\section{Introduction}

Carthamus lanatus L. (Asteraceae) is a biennial plant growing in the Mediterranean, which possesses sedative, anti-tumor and interferon-inducing activities (Benedi et al., 1986; Yasuhuko et al., 1979). Phytochemical studies of the species resulted in isolation of sesquiterpene glycosides (Feliciano et al., 1990), flavonoids (El-Shaer et al., 1998; Novruzov and Shamsizade, 1998), aromatic acids, serotonins (Lahloub et al., 1993), lipids (Demir et al., 1978), amino acids, carbohydrates (Yasuhuko et al., 1979). Sterols and triterpenes isolated from $C$. tinctorius species were found to possess important biological activities, which encourages studies on these compounds. GC/MS studies on the composition of sterols, triterpenes, volatiles and other constituents in aerial parts of $C$. lanatus collected in Bulgaria are presented. Most of the compounds were found for the first time for this species. The cytotoxicity of the main fractions was studied and the biological activity of many individual compounds shortly reviewed.

\section{Experimental}

Plant material

Aerial parts of Carthamus lanatus were collected in July at the Losen village region. A voucher specimen (No 156639) is deposited in the Herbarium of the Institute of Botany, Bulgarian
Academy of Sciences (SOM). The plant was identified by Dr. Rilka Taskova.

\section{Isolation and GC/MS analysis of sterols and triterpenes}

$1.5 \mathrm{~kg}$ dry and ground aerial parts of C. lanatus were consecutively extracted with $15 \mathrm{l}$ dichloromethane and 151 methanol. The concentrated dichloromethane $(29 \mathrm{~g})$ was partitioned between upper and lower (12 g) layer of hexane-methanolwater (19:19:2, v/v/v). Part (5 g) of the lower layer of the partitioned dichloromethane extract was separated on silica gel (Merck) column with hexane and hexane/ethylacetate (20:1 to $1: 10, \mathrm{v} / \mathrm{v})$ (20 $\mathrm{ml}$ fractions were collected). Crude fr. 43-49 (28 mg; fraction A; triterpene mixture: on TLC with $\mathrm{R}_{\mathrm{f}}$ of $\beta$-amyrine), fr. $53-57$ (31 $\mathrm{mg}$; sterol mixture) and fr. 62-64 (90 mg; fraction B; on TLC with $\mathrm{R}_{\mathrm{f}}$ of oleanolic acid) were separated and further purified by SEP-Pak $\mathrm{C}_{18}$ cartridges for rapid sample preparation (Waters, Milford, USA) with methanol. The purified samples were analysed by GC/MS.

For GC/MS a Hewlett Packard gas chromatograph 6890 series II Plus linked to Hewlett Packard mass spectrometer system equipped with a capillary column HP5-MS $(30 \mathrm{~m} \times 0.25 \mathrm{~mm}$, $0.25 \mu \mathrm{m}$ film thickness) was used. The temperature was programmed from $230{ }^{\circ} \mathrm{C}$ to $300{ }^{\circ} \mathrm{C}$ at a rate 
of $4{ }^{\circ} \mathrm{C} \mathrm{min}-1$ with $10 \mathrm{~min}$ hold. Injector was at $280^{\circ} \mathrm{C}$. Helium was used as a carrier gas with a

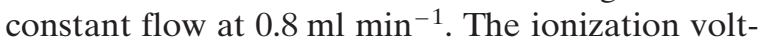
age was $70 \mathrm{eV}$. Fraction B was analyzed also after silylation at the conditions given for the silylated polar compounds mentioned below.

Quantitative analysis of sterols was performed on a Hewlett Packard gas chromatograph 5890 equipped with FID and capillary column HP5-MS (30 $\mathrm{m} \times 0.25 \mathrm{~mm}, 0.25 \mu \mathrm{m}$ film thickness), at $230{ }^{\circ} \mathrm{C}$ and programmed to $300{ }^{\circ} \mathrm{C}$ at $4{ }^{\circ} \mathrm{C} \mathrm{min}{ }^{-1}$ and $10 \mathrm{~min}$ hold. Injector and detector were at $280{ }^{\circ} \mathrm{C} .1 \mu \mathrm{l}$ of each sample were injected triplicate split/spiltless and quantities represented as relative area $\%$ as derived from the intergrator.

\section{Isolation and analysis of volatiles}

Two samples of $C$. lanatus of fresh minced aerial parts and flowers were subjected for $4 \mathrm{~h}$ distillation-extraction in a Likens-Nickerson apparatus. The volatiles were collected in diethyl ether and dried over anhydrous $\mathrm{Na}_{2} \mathrm{SO}_{4}(0.06 \%$ and $0.02 \%$ of dry wt). The GC/MS analysis was performed with GC/MS equipped with a capillary column HP5-MS (30 m $\times 0.25 \mathrm{~mm}, 0.25 \mu \mathrm{m}$ film thickness). The temperature was programmed from $40{ }^{\circ} \mathrm{C}$ to $280{ }^{\circ} \mathrm{C}$ at a rate of $6^{\circ} \mathrm{C} \mathrm{min}^{-1}$. The ion source was set at $250^{\circ} \mathrm{C}$. Helium was used as a carrier gas

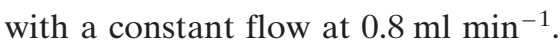

\section{Isolation and analysis of polar compounds}

Fresh aerial parts were minced and extracted with methanol. Water was added to the concentrate and successive extraction with trichloromethane and $n$-butanol was carried out. $5 \mathrm{mg}$ of the concentrated butanol extract were subjected to silylation with $50 \mu \mathrm{l}$ pyridine and $75 \mu \mathrm{l}$ bis(trimethylsilyl)trifluoroacetamide (BSTFA). The mixture was heated at $80^{\circ} \mathrm{C}$ for $30 \mathrm{~min}$ and analyzed by GC/MS equipped with a capillary column HP5-MS $\left(30 \mathrm{~m} \times 0.25 \mathrm{~mm}, 0.25 \mu \mathrm{m}\right.$ film) at $100{ }^{\circ} \mathrm{C}$ and programmed to $300{ }^{\circ} \mathrm{C}$ at $5^{\circ} \mathrm{C} \mathrm{min}-1$ and $10 \mathrm{~min}$ hold. Injector temperature $280^{\circ} \mathrm{C}$.

\section{Identification of compounds by GC/MS analysis}

The identification was accomplished using computer searches by NIST98 Wiley MS Data library. In some cases where identical spectra were not found only the structural type of the component was proposed based on the MS fragmentation. When possible reference compounds were cochromatographed to confirm GC retention times.

\section{Cytotoxicity assay}

The brine shrimp (Artemia salina) assay was performed in triplicate with appropriate amounts of samples dissolved in DMSO ( $1 \%$ final volume) using 10 freshly hatched larvae, suspended in $5 \mathrm{ml}$ artificial sea water (Solis et al., 1993; De Rosa et al., 1994). Concentrations of 1, 0.1, 0.01 and $0.001 \mathrm{mg} / \mathrm{ml}$ were used. For each dose tested deaths and survivors were counted after $24 \mathrm{~h}$ and data statistically analyzed by the Finney program, which affords $\mathrm{LC}_{50}$ values with $95 \%$ confidence intervals. Caffeic acid phenetyl ester (CAPE) was used as active reference substance.

\section{Results and Discussion}

\section{Sterol composition}

Sterols are important constituents of all eukaryotes and play vital role in plant cell membranes. Plant sterols possess valuable physiological activities, they are biogenetic precursors of many hormones and oviposition stimulants of some insects (Harborne, 2001).

The sterol fraction was analyzed by GC/MS. The data are summarized in Table I. Three groups of sterols were found together, sterols with double

Table I. Sterol composition (\% of the total sterol fraction)*.

\begin{tabular}{|c|c|}
\hline Sterol & $\underset{\%}{\text { Abundance }}$ \\
\hline Cholesterol & 0.5 \\
\hline Ergost-5-en-3 $\beta$-ol (campesterol) & 3.4 \\
\hline 24-Methylcholestan-3-ol & 2.1 \\
\hline $\begin{array}{l}\text { 24-Ethylcholesta-5,22-dien-3 } \beta \text {-ol } \\
\text { (stigmasterol) }\end{array}$ & 25.1 \\
\hline 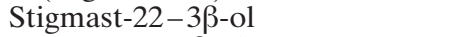 & 0.7 \\
\hline 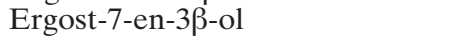 & 1.8 \\
\hline Stigmasta-7,25-diene-3 $\beta$-ol & 1.5 \\
\hline 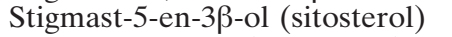 & 45.1 \\
\hline Stigmastan-3 $\beta$-ol (fucostanol) & 5.1 \\
\hline 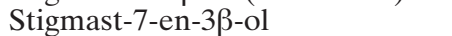 & 13.8 \\
\hline
\end{tabular}

* Values obtained from three parallel measurements. The standard deviations (related to peak proportion on the chromatograms) are as follows: \pm 0.3 for cholesterol and \pm 0.1 for the others. 
bonds at C-5 or C-7 and stanols with $\Delta^{5}$-sterols prevailing. The typical plant sterols, sitosterol and stigmasterol, appeared as main sterol components, while cholesterol was present in negligible concentrations. Sitosterol possesses antihyperlipoproteinaemic, antibacterial and antimicotic activity and has been shown to act as inhibitor of tumor promotion in vivo (Yasukawa et al., 1991) and to inhibit carcinogenesis (Raicht et al., 1980). Stigmasterol was found to markedly inhibit tumor promotion in two-stage carcinogenesis in mice (Kasahara et al., 1994; Yasukawa et al., 1991) and to exhibit significant inhibitory effect on HIV reverse transcriptase (Akihisa et al., 2001). A mixture of stigmasterol and sitosterol was shown to possess anti-inflammatory activity after topical application (Gomez et al., 1999). Therefore, the presence of these sterols in $C$. lanatus is of practical importance.

The sterol composition of C. lanatus differed to some extent from those found in other higher plants, because usually stigmasterol is not among the main sterols in plants. However, it is the main sterol in C. lanatus and in C. tinctorius, another species of the genus (Kasahara et al., 1994). Hence high concentrations of stigmasterol might be a distinguishing characteristics of the genus Carthamus.

Two stanols, 24-methylcholestan-3-ol (campestanol) and fucostanol, were identified within this study. Campestanol is distributed in plant oils consumed in human diets, which is not accumulated when fed and incorporated into the diet may block cholesterol absorption (Xu et al., 1999). Stigmastan-3-ol has been reported to inhibit HIV-1 reverse transcriptase (Akihisa et al., 2001). Sterols with C-7 double bond occur relatively seldom in plants. They could be used for treatment of some prostate problems (Gomez et al., 1999).

The complex composition and the variety of biological activities of sterol compounds in C. lanatus show the potential of future investigations on chemotaxonomy and practical application of this species.

\section{Triterpene composition}

Triterpenes attract attention because of their biological activities. Two fractions of different polarity (fractions $\mathrm{A}$ and $\mathrm{B}$ corresponding to zones with $\mathrm{R}_{\mathrm{f}}$ of amyrine and oleanolic acid) were separated and investigated. The fractions were isolated after column chromatography and purified by SEP-Pak $\mathrm{C}_{18}$ cartridges. The analysis of fraction $\mathrm{A}$ was performed without derivatization by means of GC/MS (Table II). In fraction A prevailed taraxasterol, followed by $\beta$-amyrine and $\alpha$-amyrine. Taraxasterol was shown to exhibit considerable activity against 12-O-tetradecanoylphorbol-13-acetate (TPA)-induced inflammatory ear oedema in mice and tumor promotion in mouse skin (Akihisa et al., 1996). Triterpene alcohols from Compositae flowers were demonstrated to possess marked anti-inflammatory activity (Akihisa et al., 1996). Taraxerol possesses antiulcer properties. $\alpha$-Amyrine, lupeol and cycloartan-type triterpenes are cytotoxic agents (Banskota et al., 1999).

The more polar fraction B was analysed as such and after silylation by GC/MS (Table II). Different type of compounds were found in this fraction. Dehydroabietic acid was present in considerable amounts. Dehydroabietic acid is an antibacterial (Soderberg et al., 1990), antiinflammatory (Li and McChesney, 1992) and potential antitumor-promoting (Kinouchi et al., 2000) agent. The identified betulin is antineoplastic agent. Inhibitory effect on TPA-induced inflammation and inhibitory activities against tumor promotion in mice of this triterpenoid was shown (Yasukawa et al., 1991). Three flavone aglycons, three anthraquinones and vitamin E were identified. Flavonoids possess anticarcinogenic and anti-inflammatory properties. Chrysin is anti-inflammatory and antibacterial agent and recently have been found to exhibit anti-HIV-activity (Wang et al., 1998). Two of the main constituents of this fraction with molecular mass 410 were not identified because of the lack of reference compounds. Among the carboxylic acids prevailed hexadecanoic acid. The fatty acids are well known active metabolites. They serve as an important energetic substrate for the cells. Linoleic acid is essential for maintenance of growth and $\alpha$-linolenic acid for neural functions. Both acids were shown to be potent cycloxygenase-2 (COX-2) catalyzed prostaglandin biosynthesis inhibitors (Ringbom et al., 2001).

\section{Volatiles}

Volatile compounds often possess valuable biological activities. They serve as allelochemicals defending plants from bacteria, fungi and viruses and 
Table II. Triterpene composition (fraction A, zone with $R_{f}$ of amyrine) and composition of fraction B (zone with $R_{f}$ of oleanolic acid) analyzed by direct GC/MS and after silylation $(\%)^{*}$.

\begin{tabular}{|c|c|}
\hline Compound & $\underset{\%}{\text { Abundance }}$ \\
\hline
\end{tabular}

\section{Triterpene composition**}

Eicosanol***

Helianol

Tarax-14-en-3 $\beta$-ol (taraxerol)

0.3

Olean-12-en-3 $\beta$ ( $\beta$-amyrine)

Urs-12-en-3 $\beta$-ol ( $\alpha$-amyrine)

Lup-20(29)en-3 $\beta$-ol (lupeol)

24-Methylenecycloartan-3 $\beta$-ol

(24-methylenecycloartanol)

Hop 22(29)-3-one

Hop-22(29)-3-ol

Taraxast-20(30)-en-3 $\beta$-ol (taraxasterol)

12.0

9.6

0.3

3.8

0.8

2.0

65.2

\section{Composition of fraction $\boldsymbol{B}^{* *}$}

Acids

Eicosanoic acid

Terpenes

Dehydroabietic acid

Flavonoids

5-Hydroxy-6,7-dimethoxy-flavone

5-Hydroxy-7-methoxy-flavone

Chrysin

Others

Vitamin E

Unidentified M 410

Unidentified M 410

Betulin isomer

Betulin

\section{Composition of silylated fraction $B$}

\section{Carboxylic acids}

2-Hydroxy-propanoic acid

Dodecanoic acid

Tetradecanoic acid

Pentadecanoic acid

Hexadecanoic acid

Heptadecanoic acid

Linoleic acid

$\alpha$-Linolenic acid

Octadecanoic acid

Eicosanoic acid

Terpenes

Dihydroactinidiolide

Dehydroabietic acid

Phenolics

3-Methoxy-4-hydroxy-benzaldehyde

2-Methoxy-4-(1-propenyl)-phenol

3-Methoxy-4-(1-propenyl)hydroxy-

benzaldehyde

Anthraquinones

1-Hydroxy-3-methoxy-6-

methylanthraquinone

1,6-Dihydroxy-3-methylanthraquinone
Table II. (cont.)

\begin{tabular}{lc}
\hline Compound & $\begin{array}{c}\text { Abundance } \\
\%\end{array}$ \\
\hline 1,6-Dihydroxy-8-methoxy-3- & 0.5 \\
methylanthraquinone & \\
Others & \\
Unidentified M 410 & 17.3 \\
Unidentified M 410 & 9.0 \\
\hline
\end{tabular}

* The ion current generated depends on the characteristics of the compound and is not a true quantitation. ** Analyzed by direct GC/MS.

*** The non-triterpene alcohol eicosanol present in this fraction is also included.

take part in plant-insect relationships. The volatiles from flowers and aerial parts of $C$. lanatus were obtained by distillation-extraction and analyzed by GC/MS. The data obtained are sumarized in Table III.

As it was expected, the hydrocarbons were present in higher concentrations in the volatiles from flowers. Saturated straight chain hydrocarbons with 21-31 carbon atoms were identified. The main hydrocarbons in the flowers contained $23-$ 27 carbon atoms and, respectively, 25-31 carbon atoms in the aerial parts. Hydrocarbons with odd number of carbon atoms predominated in both samples, especially in the flowers. Acetylenic compounds are known to be present in Carthamus species (Chapman and Hall, 1996). 3-Tetradecene-1yne was identified in the volatile fraction isolated from flower and aerial parts. Two other constituents showed mass spectral fragmentation typical for such compounds, but their structures could not be determined. Toluene was found only in low concentrations in the flowers.

Terpenoids are an important part of volatiles from plants. Most of them possess different allelochemical functions. In $C$. lanatus were identified two sesquiterpenes, $\alpha$-bisabolol and caryophyllene oxide. $\alpha$-Bisabolol fucopyranoside is a main constituent of C. lanatus (Feliciano et al., 1990). Now the free sesquiterpene alcohol was found. $\alpha$-Bisabolol possesses antibacterial and antifungal activities, which indicates defensive functions in the investigated plant. Caryophyllene oxide is well known as preservative in food, drugs and cosmetics. It is an antibacterial and antifungal agent (Yang et al., 1999), suggested as potential anticar- 
Table III. Volatile compounds from C. lanatus ( $\%$ from the total volatiles)*.

\begin{tabular}{|c|c|c|}
\hline Compounds & $\begin{array}{l}\text { Flowers } \\
\quad(\%)\end{array}$ & $\begin{array}{l}\text { Aerial parts } \\
(\%)\end{array}$ \\
\hline \multicolumn{3}{|l|}{ Hydrocarbons } \\
\hline 3-Tetradecen-5-yne & 0.3 & 0.2 \\
\hline Heneicosane & 0.6 & 0.2 \\
\hline Docosane & 2.3 & 0.5 \\
\hline Tricosane & 7.7 & 3.0 \\
\hline Tetracosane & 8.8 & 2.1 \\
\hline Pentacosane & 9.6 & 3.3 \\
\hline Hexacosane & 6.6 & 2.7 \\
\hline Heptacosane & 8.7 & 3.5 \\
\hline Octacosane & 4.5 & 3.1 \\
\hline Nonacosaner & 3.5 & 3.6 \\
\hline Triacontane & 2.6 & 4.1 \\
\hline Hentriacontane & 2.0 & 4.7 \\
\hline \multicolumn{3}{|l|}{ Aldehydes and ketones } \\
\hline $\begin{array}{l}\text { 2,5-Furandione-3-(1,1-dimethyl } \\
\text { ethyl) }\end{array}$ & & 0.1 \\
\hline Nonanal & 0.3 & 0.1 \\
\hline Decanal & 0.2 & 0.1 \\
\hline Dodecanal & 0.2 & 0.1 \\
\hline $\begin{array}{l}\text { 2,5-Cyclohexadiene-1,4-dione-2,6- } \\
\text { bis(1,1-dimethyl ethyl) }\end{array}$ & 0.7 & 0.2 \\
\hline $\begin{array}{l}\text { 2,5-Cyclohexadiene-1-one-2,6-bis- } \\
\text { (1,1-dimethyl ethyl)-4-ethylide- } \\
\text { ne }\end{array}$ & 3.2 & 0.6 \\
\hline \multicolumn{3}{|l|}{ Acids } \\
\hline 2-Methyl butanoic acid & 0.2 & - \\
\hline \multicolumn{3}{|l|}{ Aromatics } \\
\hline Toluene & 0.1 & - \\
\hline Benzene isocyanate & 0.3 & 0.1 \\
\hline $\begin{array}{l}\text { Phenol-4,6-di-(1,1-dimethyl } \\
\text { ethyl)-2-methyl }\end{array}$ & 0.3 & 0.1 \\
\hline $\begin{array}{l}\text { Benzene-1,1'-(1,1,2,2-tetrame- } \\
\text { thyl-1,2-ethane diyl)bis }\end{array}$ & 1.2 & 0.3 \\
\hline 2,4-Diphenyl-4-methyl-1-pentene & 0.5 & 0.3 \\
\hline \multicolumn{3}{|l|}{ Terpenes } \\
\hline$\alpha$-Bisabolol & 0.6 & 0.6 \\
\hline Caryophyllene oxide & 0.3 & 0.2 \\
\hline \multicolumn{3}{|l|}{ Sulfur compounds } \\
\hline Dimethyl disulfide & 0.1 & 0.3 \\
\hline Methyl sulfonyl ethane & 0.1 & 0.1 \\
\hline 1,2-Benzisothiazole & 0.2 & 0.1 \\
\hline Cycloctanoic sulfur & 5.8 & 1.4 \\
\hline \multicolumn{3}{|l|}{ Others } \\
\hline 1,1,2,2-Tetrachloroethane & 3.4 & 1.0 \\
\hline Erucyclamide & 8.4 & 6.6 \\
\hline
\end{tabular}

* The ion current generated depends on the characteristics of the compound and is not a true quantitation. cinogenic agent (Zheng et al., 1992) and found to exhibit cytotoxic activity against several solid tumor cell lines (Kubo et al., 1996).

Aromatic compounds were also found. Phenolics usually possess antimicrobial and antifungal activities and consequently defensive functions.

Aldehydes and ketones often act as allelochemicals. Such activities were proven for the three identified by us aldehydes, decanal is attractant for some insects (Mattiacci et al., 2001; Wang et al., 1999), nonanal is a repellent (Huber and Borden, 2001; Wang et al., 1999), dodecanal has some pheromone-like activity (Cosse et al., 2002).

A few halogen-containing compounds were found in the investigated volatiles, but we succeeded to identify only 1,1,2,2-tetrachloroethane. Chlorinated ethanes were found recently in some algae and higher plants, but their functions are not clear. Some of them have a high carcinogenic potential (Greim and Wolf, 1984). The identified by us perchloroethane was shown to be cancerogenic in mice, but not in rats and also is a weak mutagene.

The volatile fraction contained some sulfur compounds including cyclooctanoic sulfur. Dimethyl disulfide and analogous compounds are found in many biologically active extracts. Dimethyl disulfide attracts some insects (Reddy et al., 2002) and is used to improve the fragrance and taste of some foods (Ren et al., 2001).

\section{Polar constituents}

After separation of the lipophylic compounds with trichloromethane from the methanol extract the aqueous part was extracted with $n$-butanol. The concentrated butanol extract was silylated and the polar constituents possessing hydroxyl, amine and carboxyl groups transformed into volatile TMS-ethers were analyzed by GC/MS. In this complex mixture were identified 29 compounds (about $25 \%$ of the mixture) belonging to different groups as alcohols, acids, hydroxy acids, polyhydroxy acids, esters, sugars, amino acids and terpenoids.

Free fatty acids and oxidized acids are important constituents of butanol fractions from higher plants, algae and invertebrates. The main fatty acids of the plant were found in free state. Such free acids possess defensive functions in plants, be- 
cause of their insecticidal and antimicrobial activity (Kanias et al., 1992). Caffeic acid possesses antimicrobial, antifungal and antiviral activities. Benzenepropionic acid and its $\alpha$-hydroxy derivative are relatively rare in higher plants and can be used as a characteristic feature of $C$. lanatus. 2Hydroxy propanoic acid is regularly identified in butanol fractions of higher plants and algae, whereas malic acid and butanedioic acid are characteristic for some higher plants. 3-Methoxy-4hydroxy benzoic acid is a defensive compound in plants, due to its antibacterial and antifungal activities. Similar activity might possess the phosphoric acid methyl ester.

The presence of the amino acid prolin was also established.

As it was expected carbohydrates were found in this fraction. Significant concentrations of glucose and fructose were identified, followed by lower concentrations of sucrose. myo-Inositol and an unidentified isomer were also present.

Sulfates often have valuable biological activities. Two terpenoid sulfur derivatives, menthyl $t$-butyl sulfinate and dimenthyl sulfite, were identified in the butanol fraction, which could contribute to the biological activities of the investigated plant.

Unexpected, sitosterol and stigmasterol were found in the polar fraction. According to the extraction procedure the sterols should be completely extracted with trichloromethane from the total extract, where were identified as mentioned above. Sitosterol and stigmasterol, which were found in the butanol fraction, might be explained with presence of unstable complexes of sterols with polar compounds like sugars, amino acids,

Akihisa T., Ogihara J., Kato J., Yasukawa K., Ukiya M., Yamanouchi S., and Oishi K. (2001), Inhibitory effects of triterpenoids and sterols on human immunodeficiency virus-1 reverse transcriptase. Lipids 36, 507-512.

Akihisa T., Yasukawa K., Oinuma H., Yoshimasa K., Sakae T., Michio T., Kumaki K., and Tamura T. (1996), Triterpene alcohols from the flowers of Compositae and their anti-inflammatory effects. Phytochemistry 43, 1255-1260

Banskota A., Tezuka Y., Tran K., Tanaka K., Saiki I., and Kadota Sh. (1999), Thirteen novel cycloartanetype triterpenes from Combretum quandrangulare. J. Nat. Prod. 63, 57-64. etc. not soluble in trichloromethane. Such complexes should remain in the polar fractions. Probably through the silylation procedure they undergo destruction and set free the sterols, which form TMS ethers. Recently, in two marine sponges (Chondrosia reniformis and Verongia aerophoba) significant amount of sterols were found in the butanol fraction by the same procedure (Nechev et al., 2002).

\section{Cytotoxic activity}

Six fractions from $C$. lanatus were screened for cytotoxic activity by using Brine shrimp (Artemia salina) assay and as active reference substance, caffeic acid phenetyl ester (CAPE), $\left(\mathrm{LD}_{50}=\right.$ $0.45 \pm 0.05 \mu \mathrm{g} / \mathrm{ml})$. The water/methanol fraction of the dichloromethane extract showed a significant higher activity $\left(\mathrm{LD}_{50} 47.99 \pm 17.49\right)$ than the butanol fraction of the methanol extract $\left(\mathrm{LD}_{50}>1000\right)$. After separation of the former three sub-fractions were obtained and two of them, fraction $\mathrm{B}\left(\mathrm{LD}_{50}\right.$ $1.57 \pm 1.25)$ and the sterol fraction $\left(\mathrm{LD}_{50} 13.99 \pm\right.$ 9.10), showed even higher activities. The volatile fraction exhibited also a strong cytotoxic activity $\left(\mathrm{LD}_{50} 4.37 \pm 1.14\right)$.

It could be concluded that $C$. lanatus contains various bioactive compounds including such with strong cytotoxic activity and could be recommended as a plant of phytopharmaceutical importance.

\section{Acknowledgement}

This research is supported by Deutsche Forschungsgemeinschaft (DFG).

Benedi J., Iglesias I., Manzanares J., and Zaragoza F. (1986), Preliminary pharmacological studies of Carthamus lanatus L. Plant Med. Phytother. 20, 2530.

Cosse A., Bartelt R., Weaver D., and Zilikowski B. (2002), Pheromone components of the wheat stem sawfly: identification, electrophysiology and field bioassay. J. Chem. Ecol. 28, 407-423.

Dictionary of natural products on CD-ROM. (1996) Chapman \& Hall. Electronic Publ. Division.

El-Shaer N., Shaaban E., Abou-Karam M., and El-Din A. (1998), Flavonoids from Carthamus lanatus. Alex. J. Pharm. Sci. 12, 23-26. 
Demir L., Nedim A., and Marquard R. (1978), The fatty acid pattern and tocopherol content as different characteristics of Carthamus species found in Turkey. Ange Bot. 52, 313-319.

De Rosa S., De Giulio A., Crispino A., Iodice I., and Tommonaro G. (1997), Further bioactive sesterterpenes from the tyrrhenian sponge Fasciospongia $\mathrm{Ca}$ vernosa. Nat. Prod. Lett. 10, 267-274.

Feliciano A., Medarde M., Del Rey B., Del Corral J., and Barrero A. (1990), Eudesmane glycosides from Carthamus lanatus. Phytochemistry 29, 3207-3211 and ref. cited therein.

Gomez M., Saenz M., Garcia M., and Farnandez M. (1999), Study on topical anti-inflammatory activity of Achillea ageratum on chronic and acute inflammation. Z. Naturforsch. 55c, 937-941.

Greim H., and Wolf T. (1984), Carcinogenicity of organic halogenated compounds. In: Chemical carcinogenesis (Searle C., ed.). Vol. 1, 2nd edn. Am. Chem. Soc., Washington DC, pp. 525-575.

Harborne J. (2001), Twenty-five years of chemical ecology. Nat. Prod. Reports 18, 361-379.

Huber D., and Borden J. (2001), Angiosperm bark volatiles disrupt response of Douglas-Fir beetle, Dendroctonus pseudotsugae to attractant-baited traps. J. Chem. Ecol. 27, 217-232.

Kanias G., Skaltsa E., Tsitsa E., Loukis A., and Bitis J. (1992), Study of the correlation between trace elements, sterols and fatty acids in brown algae from Saranikos Gulf of Greece. Fresenius' J. Anal. Chem. 344, 334-339.

Kasahara Y., Kumaki K., Katagiri S., Yasukawa K., Yamanouchi S., Takido M., Akihisa T., and Tamuta T. (1994), Carthami flos extract and its component, stigmasterol, inhibit tumour promotion in mouse skin two-stage carcinogenesis. Phytotherapy Res. 68, 327-331.

Kinouchi Y., Ohtsu H., Tokuda H., Nishino H., Matsunaga S., and Tanaka T. (2000), Potential antitumorpromoting diterpenoids from the stem bark of Picea glehni. J. Nat. Prod. 63, 817-820.

Kubo I., Chaudhuri S., Kubo Y., Sanchez Y., Ogura T., Saito T., Isikawa H., and Haraguchi H. (1996), Cytotoxic and antioxidative sesquiterpenoids from Heterotheca inuloides. Planta Med. 62, 427-430.

Lahloub M., Amor M., El-Khajaat S., and Haraz F. (1993), A new serotonin derivative from seeds of Carthamus lanatus L. Mans. J. Pharm. Sci. 9, 234-243.

Li W. and McChesney J. (1992), Preparation of potential anti-inflammatory agents from dehydroabietic acid. J. Pharm. Sci. 81, 646-651.

Mattiacci L., Rocca B., Scascighini N., D’Alessandro M., Hern A., and Dorn S. (2001), Systemically induced plant volatiles emitted at the time of "danger". J. Chem. Ecol. 27, 2233-2251.

Nechev J., Christie W., Robaina R., de Diego F., Popov S., and Stefanof K. (2002), Lipid composition of the sponge Verongia aerophoba from the Canary islands. Eur. J. Lipid Sci. Technol. 104 (in press).

Novruzov E., and Shamsizade L. (1998), Anthocyans of Carthamus species. Chem. Nat. Comp. 34, 514-515.

Raicht R., Cohen B., and Fazzini E. (1980), Protective effect of plant sterols against chemically induced colon tumours in rats. Cancer Res. 40, 403-405.

Reddy G., Holopainen J., and Guerrero A. (2002), Olfactory responses of Plutella xylostella natural enemies to host pheromone, larval frass, and green leaf cabbage volatiles. J. Chem. Ecol. 28, 131-143.

Ren Y., Desmarchelier J., Williams Ph., and Delves R. (2001), Natural levels of dimethyl sulfide in rough rice and its products. J. Agric. Food Chem. 49, 705709.

Ringbom T., Huss U., Stenholm A., Flock S., Skatteboel P., Perera P., and Bohlin L. (2001), COX-2-inhibitory effects on naturally occurring and modified fatty acids. J. Nat. Prod. 64, 745-749.

Soderberg T., Gref R., Holm S., Elmros T., and Hallmans G. (1990), Antibacterial activity of rosin and resin acids in vitro. Scand. J. Plast reconstr. Surg Hand Surg. 24, 199-205.

Solis P., Wright C., Anderson M., Gupta M., and Philippson J. (1993), A microwell cytotoxicity assay using Artemia salina (brine shrimp). Planta Med. 59, 250252.

Wang H., Xia Y., Yang Z., Natschke S., and Lee K. (1998), Recent advances in the disovery and development of flavonoids and their analogues as antitumor and anti-HIV agents. Adv. Exp. Med. Biol. 439, $191-225$.

Wang S., Ghisalberti E., and Ridsdill-Smith J. (1999), Volatiles from Trifolium as feeding detergents of redegged mites. Planta Med. 52, 601-605.

Xu G., Salen G., Tint G. S., Batta A. K., and Shefer S. (1999), Campestanol (24-methyl-5alpha-cholestan3beta-ol) absorption and distribution in New Zealand White rabbits: effect of dietary sitostanol. Metabolism 48, 363-368.

Yang D., Michel L., Chaumont J., and Millet-Clerc J. (1999), Use of caryophyllene oxide as an antifungal agent in an in vitro experimental model of onychomycosis. Mycopathologia 148, 79-82.

Yasuhuko K., Kanagawa Y., Seishi K., and Takashi H. Wasserloeslicher Interferoninduktor, Verfahren $\mathrm{zu}$ seiner Gewinnung und dessen Verwendung. Ger Offen 3,004,018 Appl. 07 Feb. 1979.

Yasukawa K., Takido M., Matsumoto T., Takeuchi M., and Nakagawa S. (1991), Sterol and triterpene derivatives from plants inhibit the effects of tumour promoter and sitosterol and betulinic acid inhibit tumour formation in mouse skin two-stage carcinogenesis. Oncology 41, 72-76.

Zheng G., Kenney P., and Lam L. (1992), Sesquiterpenes from clove (Eugenia caryophyllata) as potential anticarcinogenic agents. J. Nat. Prod. 55, 999-1003. 